\title{
VALORES ORGANIZACIONAIS NUMA INSTITUIÇÃO PÚBLICA DE ENSINO DO RN
}

\author{
M. S. O. C. VIEIRA' e D. C. GOMES ${ }^{2}$ \\ 'Universidade Estadual Vale do Acaraú - UVA; Especialista em Gestão de Pessoas \\ ${ }^{2}$ Câmpus Currais Novos - IFRN; Mestre em Administração \\ solidadecesario2005@yahoo.com.br ${ }^{1}$-danilo.cortez@ifrn.edu.br ${ }^{2}$
}

Artigo submetido em maio/2012 e aceito em junho/2013

\section{RESUMO}

Os valores organizacionais são compreendidos como princípios e crenças que orientam o funcionamento da organização, fundamentando a cultura organizacional do ponto de vista dos indivíduos nela inseridos. Dessa forma, esta pesquisa buscou identificar e relatar os valores organizacionais da UFRN/Campus de Currais Novos, através da descrição desses valores sob a percepção dos indivíduos nela presentes. Nesse sentido, fez-se necessário entender os valores pessoais e organizacionais, bem como o comprometimento e o comportamento organizacional pautados nesses valores pesquisados. A pesquisa exploratória descritiva utilizou como instrumento de coleta o Inventário de Valores Organizacionais - IVO, validado por Tamayo, Mendes e Paz (2000). O público alvo da pesquisa constituiu-se de todos os servidores (docentes e técnicos administrativos) da UFRN/Campus de Currais Novos, totalizando 57 servidores. Os resultados encontrados revelaram que os valores organizacionais, de maior importância para a instituição pesquisada, estão relacionados à hierarquia. Em contrapartida, os valores que detêm menor importância estão relacionados a igualitarismo.

PALAVRAS-CHAVE: gestão de pessoas, valores organizacionais, comportamento organizacional.

\section{ORGANIZATIONAL VALUES IN A PUBLIC INSTITUTION OF EDUCATION RN}

\begin{abstract}
Organizational values are understood as principles and beliefs that guide the running of the institution, basing the organizational culture from the point of view of people who are inserted on it. Thereby, this research tried to identify and to relate the organizational values of UFRN/Campus of Currais Novos, through the description about these values under the perception of individuals present on it. Accordingly, it was necessary to understand the personal and organizational values, as well as the organizational commitment and behavior ruled in the researched values. The exploratory and
\end{abstract}

descriptive research used as instrument of study the Inventário de Valores Organizacionais - IVO, validated by Tamayo, Mendes and Paz (2000). The target group of the research was constituted by every employee (professors and administrative assistant) of UFRN/Campus of Currais Novos, totaling 57 employee. The revealed results showed that the organizational values, more import to the researched institution, are associated to hierarchy. On the other hand, values that had lower importance are related to egalitarianism.

KEYWORDS: management of people, organizational values, organizational behavior. 


\section{VALORES ORGANIZACIONAIS NUMA INSTITUIÇÃO PÚBLICA DE ENSINO DO RN}

\section{INTRODUÇÃO}

Nas organizações, o recurso humano constitui o mais valioso dos recursos pelo fato das pessoas serem dotadas de habilidades, capacidades, conhecimentos e comportamentos. A gestão de pessoas aborda este assunto dentro de um contexto comportamental entre pessoa e organização, ou seja, o comportamento da pessoa em relação à sua organização e da organização em relação à pessoa.

Segundo Bergamini (2008) os estudos sobre o comportamento humano, dentro das organizações, procuram entender como as pessoas vivem e resolvem seus problemas dentro do ambiente de trabalho. Diferentemente dos outros recursos, a gestão nas organizações tem deixado claro que o elemento humano se caracteriza como fator de extrema importância no que se refere ao comprometimento de se chegar aos objetivos organizacionais pretendidos.

Tamayo e Gondim (1996) definem o comportamento organizacional a partir de valores existentes na organização. No Brasil, eles foram pioneiros no estudo dos valores organizacionais a partir da percepção dos empregados, e seguindo o pensamento de Shalom H. Schwartz, autor da teoria dos valores humanos básicos, construíram e validaram instrumentos de pesquisa que viabilizam avaliar os valores organizacionais tais como eles existem na mente dos empregados.

Seguindo esta linha de raciocínio, a pesquisa justifica-se pela necessidade de aprofundar os conhecimentos na área de gestão de pessoas, especificamente em valores organizacionais, aliando a teoria à prática, considerando que o contexto organizacional articula e direciona interesses e objetivos que são comuns a todos os integrantes. No entanto, esses valores são evidenciados e avaliados de forma diferenciada por cada membro inserido na organização, sendo cada indivíduo apropriado dos seus valores.

Deste modo, esta pesquisa tem como objetivo identificar os valores organizacionais do Campus de Currais Novos para melhor analisar e conhecer o comportamento organizacional da instituição, através de uma investigação cuja finalidade foi pesquisar os valores organizacionais a partir da percepção dos servidores nela inseridos.

Para Tamayo (1998), a percepção dos valores organizacionais pelos empregados estabelece uma imagem da empresa quanto a sua eficiência, tendências à inovação, tipo de gestão, e a interação entre os empregados. As características dessa imagem determinam a identificação do empregado com a empresa e com os seus objetivos.

Os estudos do comportamento organizacional levam a um entendimento de que os valores organizacionais podem ser considerados uma consequência dos valores individuais, levando-se em consideração que a função dos valores consiste em orientar a organização, guiando o comportamento de seus membros na forma de pensar, agir, sentir e de maneira que haja uma interação mútua.

Com base nesses argumentos, a problemática da pesquisa condiciona o seguinte questionamento: Quais valores organizacionais, na visão dos servidores, são priorizados na UFRN/Campus de Currais Novos? 
O presente artigo está dividido em partes, iniciando pela introdução, na qual estão presentes elementos de justificativa, sua contextualização e problema, bem como os objetivos. Em seguida, apresenta-se a fundamentação teórica que fundamentou a elaboração do trabalho e discorre acerca dos temas que dizem respeito às teorias defendidas pelos autores citados, com referência a valores organizacionais; função dos valores pessoais e organizacionais; comportamento organizacional e comprometimento. Posteriormente, descrevem-se os procedimentos metodológicos utilizados na pesquisa, que precede a parte que trata da análise dos dados, que versa sob a luz da teoria e sobre os resultados obtidos após a aplicação do inventário de valores organizacionais - IVO. Por fim, encontram-se as considerações finais e as referências bibliográficas que apresentam as obras e seus respectivos autores que serviram de embasamento teórico para este trabalho. Destaca-se, ainda, em apêndice, o instrumento (IVO) utilizado para a coleta dos dados.

\section{FUNDAMENTAÇÃO TEÓRICA}

\subsection{Valores organizacionais}

Entende-se por valores, um conjunto de princípios e crenças que se considera importante e que são evidenciados através das características de um indivíduo ou grupo, e que influencia a forma de pensar e agir de cada indivíduo, ou seja, são os valores que orientam as ações e eles existem consciente ou inconscientemente na personalidade do indivíduo. Da mesma forma os valores estão presentes nas organizações influenciando, direta ou indiretamente, no comportamento organizacional.

Para Oliveira \& Tamayo, 2004 (Apud DELFINO, LAND \& SILVA, 2010, p. 70), "Valores organizacionais podem ser considerados como o reflexo dos valores individuais considerados em conjunto. Qualquer grupo reflete valores e crenças originais de alguém". Entende-se, portanto, que valores organizacionais são aspectos que definem como os profissionais da organização se comportam e nos quais se estabelecem as relações organizacionais formando o clima e a cultura da organização.

Quanto à importância dos valores dos organizacionais, Tamayo (1998, p. 57), descreve o seguinte: "A importância atribuída por uma organização a certos valores pode determinar a quantidade de esforço investida por seus membros na emissão de certos comportamentos, bem como a sua persistência na execução dos mesmos".

Seguindo esta linha de raciocínio, fica o entendimento de que o reconhecimento dos valores, por parte da organização, gera fatores positivos como satisfação no trabalho e o comprometimento profissional dos que a fazem.

De acordo com Tamayo (1998) a percepção dos valores de uma organização e os comportamentos de comprometimento estão relacionados com afetividade, cidadania organizacional e satisfação no trabalho. O comprometimento afetivo se define como um estado em que o indivíduo se identifica com a organização e com os seus objetivos partilhando o desejo de alcançá-los. Compreende-se, ainda, por comprometimento a identificação e a lealdade do servidor com a instituição e o envolvimento com a função por ele desempenhada. Desse modo, considera-se que o estudo dos valores organizacionais deve ter como referência os valores humanos, uma vez que estes valores se originam na motivação humana. 


\subsection{Função dos valores pessoais e organizacionais}

As organizações estão inseridas em um ambiente de constantes mudanças econômicas, políticas e sociais ocasionando impacto sobre o ambiente de trabalho e sobre as relações entre indivíduos e organizações. A partir dessas mudanças surge a necessidade da sobrevivência organizacional. E, dentro desta necessidade, os valores se apresentam como norteadores da vida funcional da instituição seja ela pública ou privada. São os valores que formam a personalidade da empresa, o comportamento dos seus servidores e a rotina de funcionamento de toda e qualquer instituição.

De acordo com Gomes (2009, p. 22) "Os seres humanos possuem características distintas e intrigantes, principalmente referindo-se à análise dos comportamentos e diversidade de personalidades, aspirações e desejos entre estes".

Segundo Gouveia (2008), os valores, na organização, assume duas funções: 1 - guiar as ações humanas (tipo de orientação); 2 - Expressar suas necessidades (tipo de motivador). Para a primeira função dos valores o autor afirma que "a função dos valores como guia de comportamentos humanos é identificada pela dimensão funcional denominada tipo de orientação, com três possibilidades: social, central e pessoal". Para a segunda função dos valores o autor conclui o seguinte: "a segunda função dos valores é dar expressão cognitiva às necessidades humanas, identificada pela dimensão funcional do tipo motivador: materialista (pragmático) ou humanitário (idealista)".

Conforme Tamayo, Mendes \& Paz (2000, p. 294), "os valores organizacionais podem fortemente influenciar o que as pessoas realmente fazem". Para eles, os valores não só influenciam o comportamento do indivíduo, como também o julgamento que ele faz do outro em relação ao sistema organizacional. Defendem ainda que, "Os valores podem ser considerados como um projeto para a organização e um esforço para atingir metas por ela fixadas. As normas organizacionais estão enraizadas nos valores e podem ser consideradas uma operacionalização dos valores organizacionais".

De acordo com Tamayo (1998) o grau na escala de valores de uma organização se estrutura no tempo, na missão e nos objetivos da empresa, e que, a fonte dos valores organizacionais é constituída por exigências da organização e dos indivíduos que a compõem. Essas exigências estão relacionadas às necessidades biológicas do indivíduo e às necessidades de sobrevivência e bem-estar da própria organização. Com referência a esta temática o teórico, acima citado, descreve o seguinte:

\footnotetext{
Os valores organizacionais têm funções importantes. A primeira delas é criar entre empregados modelos mentais semelhantes, relativos ao funcionamento e à missão da organização, evitando percepções diferentes que, certamente, teriam repercussões no comportamento e atitudes dos empregados, pois os valores são assimilados em suas estruturas cognitivas. A segunda função destacada é a contribuição dos valores na construção da identidade social da organização, tornando-a distinta em relação às demais organizações (TAMAYO, 1998, p. 66).
}

Todas as teorias funcionalistas aqui apresentadas levam ao entendimento de que os valores têm a função de viabilizar uma interação entre servidor e organização, gerando um comportamento de envolvimento focado nos objetivos da organização. $O$ envolvimento com o 
trabalho leva, conseqüentemente, o servidor a se identificar psicologicamente com o que ele faz motivando-o a um maior comprometimento com a organização.

\subsection{Comportamento organizacional e comprometimento}

Entende-se por comportamento organizacional a forma como o indivíduo apresenta sua conduta e suas atitudes como trabalhador dentro de uma organização.

Kanaane (1999), estudioso do comportamento humano nas organizações, afirma que comportamento e atitude podem ser conceituados de forma distinta uma vez que o comportamento é a reação, e atitude é a tendência à reação. Para ele, o fato de um funcionário chegar atrasado ao trabalho não significa, necessariamente, que ele não goste do que faz. Neste sentido, o autor alerta para a necessidade de que a chefia esteja atenta para captar o real significado das ações expressas no trabalho, o que implica comportamentos mais receptivos e sutis de comando, em face do trabalhador e do ambiente organizacional. Dessa forma, o comportamento da organização poderá contribuir para a integração do trabalhador ao ambiente profissional gerando um compromisso mais efetivo com a organização.

Ainda de acordo com Kanaane (1999, p. 49), "repensar a organização implica rever a estrutura de poder e de autoridade vigentes, a qualidade de vida dos indivíduos pertencentes à mesma, os padrões de relacionamentos interpessoais, sistemas de comunicação, entre outros pontos".

Sobre o comportamento organizacional atual, Gomes (2009, p.22) descreve o seguinte:

\footnotetext{
As mudanças ocorridas no ambiente organizacional partem do pressuposto de que as organizações necessitam se adequar às novas exigências de mercado, principalmente quando relacionada à competitividade, comprometimento dos colaboradores, aumento de produtividade, reestruturação organizacional, ruptura de paradigmas. Para tanto, as organizações buscam alinhar seus processos e estruturas aos novos moldes organizacionais baseado na coletividade, nos resultados e no comprometimento.
}

A compreensão da conduta humana possibilita conceber atitudes de valores, crenças, sentimentos, pensamentos referentes às situações organizacionais, levando o servidor a comprometer-se com estas situações. Por comprometimento entende-se o ato de se envolver, de se empenhar, e de se inserir no ambiente dos seus afazeres seja como pessoa ou como profissional. Nas organizações, conforme teorias expressas neste artigo, o comprometimento pode ser percebido a partir da forma como o servidor desenvolve o seu trabalho, como empenha esforços e responsabilidades em realizar suas tarefas estabelecendo um vínculo, entre ele e a organização, baseado nos seus valores.

A importância do tema comprometimento organizacional, nos dias atuais, está muito clara na medida em que as organizações sentem necessidade de compreender melhor os seus empregados. Para eles, procurar identificar as variáveis que servem de efeitos motivacionais torna estes empregados mais satisfeitos e produtivos para a organização (RODRIGUES \& FREIRE JUNIOR, 2002).

Sobre o tema comprometimento, os autores descrevem: 
O comportamento dos servidores de se sentirem muito ou pouco comprometidos com o seu trabalho, embora seja originalmente produto de sua escala de valores éticos, pode e deve ser lealmente desenvolvido pela organização através de programas motivacionais e, principalmente, pela atenção dada para oferecer saudáveis condições de vida no trabalho e na sociedade. (RODRIGUES \& FREIRE JUNIOR 2002, p. 12).

Ainda na visão dos pesquisadores Rodrigues \& Freire Junior (2002, p. 11), “o comprometimento do indivíduo com a sua organização de trabalho está intrinsecamente relacionado com a escala de valores éticos individuais, que são fatores determinantes da sua conduta e da responsabilidade social com a função".

De acordo com Robbins (1998, p. 93) o comprometimento é conceituado da seguinte forma: "compromisso organizacional é definido como um estado em que o empregado identificase com a organização e suas metas, e deseja manter-se ligado a esta organização".

Entende-se, portanto, que valores pessoais, organizacionais e comprometimento, no contexto do comportamento organizacional, devem está interligados possibilitando ao servidor a consciência do seu valor social e profissional. Também possibilita, ao servidor, internalizar a idéia de que é um dever ético proteger o seu conceito profissional e sua conduta perante a sociedade a quem presta serviços.

A partir destas teorias entende-se que comprometimento é um processo através do qual o trabalhador expressa sua preocupação com o bem-estar e o sucesso da organização em que trabalha.

\section{METODOLOGIA DA PESQUISA}

Nos procedimentos metodológicos utilizou-se, como instrumento de pesquisa, o inventário de valores organizacionais - IVO elaborado por Tamayo, Mendes e Paz (2000) contendo uma escala de 36 valores organizacionais, conforme anexo I, que levou os respondentes a avaliarem a importância desses valores, como princípios orientadores, na vida da sua organização dentro de um nível real e desejável. Os valores constantes do IVO estão compartilhados e relacionados a seis fatores motivacionais conforme apresentados na tabela abaixo:

Tabela 1: Itens correspondentes a cada um dos tipos motivacionais e coeficiente alpha

\begin{tabular}{|l|c|c|}
\hline \multicolumn{1}{|c|}{ FATOR } & ITENS & ALFHAS \\
\hline Autonomia & $1,3,4,5$ & 0,83 \\
\hline Conservadorismo & $2,7,8,11,16$ & 0,77 \\
\hline Hierarquia & $9,10,17,18,19,20,22,24,27,28$ & 0,87 \\
\hline Igualitarismo & $6,12,13,14,15,25,26$ & 0,85 \\
\hline Domínio & $21,23,31,32,33,34,35,36$. & 0,84 \\
\hline Harmonia & 29,30 & 0,85 \\
\hline
\end{tabular}

Fonte: Tamayo et al.(2000) 
Os seis tipos motivacionais do IVO, na tabela acima, avaliam de forma compartilhada os valores que expressam ideologias sobre o que seja apropriado para o bom desempenho de uma organização, a partir de seis aspectos fundamentais da vida organizacional compreendida da seguinte forma: 1 - Autonomia = a importância atribuída à procura de inovação, de criatividade e de independência na execução do trabalho; 2 - Conservadorismo = a ênfase na interdependência dos membros da organização e na obtenção de objetivos grupais; 3 - Hierarquia = a relevância de papéis hierárquicos na estrutura do relacionamento interpessoal e na distribuição de recursos e de poder; 4 - Igualitarismo = procura efetivar o bem-estar de todos os membros da organização e a sua participação nos processos decisórios; 5 - Domínio = a importância dada ao sucesso organizacional e à satisfação dos clientes; 6 - Harmonia $=0$ respeito à natureza e a procura de complementariedade organizacional. O IVO também possibilita avaliar, cada item, em dois níveis: os valores reais e os valores desejáveis. Os valores reais, na percepção do servidor, são os realmente praticados, e os valores desejáveis significam a importância que os servidores gostariam que fosse atribuída a cada um dos valores organizacionais.

Esta pesquisa é do tipo exploratória-descritiva. Exploratória porque a pesquisa tem como finalidade ampliar o conhecimento a respeito de um determinado problema. Descritiva porque procura conhecer a realidade estudada, descrevendo com exatidão os fatos e fenômenos dessa realidade (TRIVINOS apud ZANELLA, 2006).

O estudo foi realizado no Campus de Currais Novos, localizado no Sítio Totoró - Currais Novos/RN. A população-alvo constituiu-se de todos os professores e técnicos administrativos da instituição pesquisada. Portanto, esta investigação, se caracteriza como uma pesquisa do tipo censitária, tendo em vista que, optou-se, considerando o pequeno número de atores, por entrevistar toda a população de servidores, conforme especificação dos cargos abaixo:

Tabela 2: Descrição dos cargos dos servidores da UFRN/Campus de Currais Novos

\begin{tabular}{|l|c|}
\hline \multicolumn{1}{|c|}{ Cargo } & Quantidade \\
\hline Professor & 39 \\
\hline Bibliotecário & 01 \\
\hline Pedagogo & 01 \\
\hline Técnico para assuntos educacionais & 01 \\
\hline Técnico de contabilidade & 01 \\
\hline Técnico de Enfermagem & 01 \\
\hline Assistente em administração & 04 \\
\hline Assistente de aluno & 01 \\
\hline Auxiliar Administrativo & 01 \\
\hline Operador de máquina copiadora & 01 \\
\hline Copeiro & 02 \\
\hline Vigilante & 04 \\
\hline Total & $\mathbf{5 7}$ \\
\hline
\end{tabular}

Fonte: Dados da pesquisa 2011

Sobre pesquisa censitária, Zanella (2009) orienta que se escolhendo fazer uma pesquisa censitária (aquela que envolve toda a população e mais adequada no caso de populações menores), não deve se utilizar a amostragem. 


\section{ANÁLISE E DISCUSSÃO DOS RESULTADOS}

O conceito de valores organizacionais é relativamente moderno, onde as organizações atuais consideram os valores como principais fatores motivacionais do comportamento organizacional. Com base nesse princípio, a pesquisa buscou identificar os valores organizacionais do Campus de Currais Novos e conhecer o comportamento da instituição através de uma investigação cuja finalidade foi pesquisar os valores organizacionais a partir da percepção dos servidores nela inseridos. Ao final da interpretação dos dados coletados pode-se concluir que a problemática, proposta para este estudo, foi devidamente analisada conforme determina o Inventário de Valores Organizacionais - IVO validado por Tamayo, Mendes e Paz (2000).

Os resultados descritivos da pesquisa, após tabulados estão apresentados na tabela 3 com médias e desvios-padrão. Percebe-se nos resultados que os valores relacionados a igualitarismo detêm a menor média encontrada $(3,01)$, diferentemente dos valores referentes à hierarquia que alcançou a maior média $(3,47)$.

Para os teóricos citados neste trabalho, os valores organizacionais permitem identificar componentes da cultura organizacional a partir de aspectos fundamentais da vida organizacional. Os valores de igualitarismo estão relacionados à busca constante de informações, distribuição do poder pelos diversos níveis, tratamento proporcional ao mérito, oportunidades iguais para todos os funcionários, imparcialidade nas decisões administrativas, ambiente de relacionamento interorganizacional adequado e complementariedade de papéis entre organizações. Estes valores expressam a efetivação do bem-estar de todos os membros da organização e a participação dos mesmos nos processos decisórios.

No entanto, os resultados que dizem respeito aos valores de igualitarismo, no Campus de Currais Novos, apresentam uma relevância inferior aos demais valores demonstrando que, para a instituição pesquisada, estes valores não são prioritários para a sua vida organizacional conforme resultado exposto na tabela abaixo.

Tabela 3: Resultado descritivo dos valores organizacionais, na percepção dos servidores da UFRN/Campus de Currais Novos

\begin{tabular}{|l|c|c|}
\hline Valores Organizacionais & Média & Desvio-padrão \\
\hline Autonomia & 3,10 & 1,54 \\
\hline Conservadorismo & 3,36 & 1,50 \\
\hline Hierarquia & 3,47 & 1,54 \\
\hline Igualitarismo & 3,01 & 1,55 \\
\hline Domínio & 3,08 & 1,49 \\
\hline Harmonia & 3,37 & 1,37 \\
\hline
\end{tabular}

Fonte: Dados da pesquisa 2011

Numa segunda análise dos resultados apresentados na tabela 3, observa-se que todos os itens obteveram relevância mediana diante da escala de valores revelando que, na percepção dos servidores, nenhum dos valores pesquisados representa muita importância ou extrema importância para sua instituição. 
Sobre a importância dos valores, no contexto organizacional, Kanaane (1999, p. 50) conceitua o seguinte:

O conjunto de valores, normas e padrões sociais influenciam o ambiente organizacional, delimitando o que se conceitua por cultura organizacional. Esta, por sua vez, se constitui gradativamente a partir dos valores que vão sendo cultuados por seus membros. As interações sociais, expectativas e necessidades refletem os anseios dos trabalhadores assinalando o clima organizacional existente nas suas organizações.

Para Domenico e Latorre (2008, p. 253) "os valores têm funções importantes, atuando como mediadores nos conflitos, contribuindo para a solução dos problemas das organizações e, consequentemente, garantindo sua sobrevivência". Dessa forma, entende-se que os valores organizacionais além de fortalecer a cultura e a identidade organizacional, se faz necessária também pelo fato de fortalecer os princípios motivacionais do trabalhador.

Ainda analisando os resultados constantes da tabela 3 , observa-se que os valores relacionados a hierarquia alcançaram a maior média na escala dos valores organizacionais da instituição pesquisada $(3,47)$. Este valor representa a relevância dos papéis hierárquicos na estruturação do relacionamento interpessoal e na distribuição de recursos e de poder. Os valores relativos a hierarquia são: Preservação dos costumes vigentes da organização - Tradição de respeito às ordens - Respeito às pessoas com cargo de chefia - Respeitar as regras e normas estabelecidas pela organização - Controle do serviço executado - Respeito aos níveis de autoridade - Preocupação com o cumprimento de horários e compromissos - Acompanhamento e avaliação contínua das tarefas - Utilização de recursos sem causar danos meio ambiente Proteção ao meio ambiente.

Segundo Tamayo, Mendes e Paz (2000, p.308), "Somente na dimensão "Hierarquia versus Igualitarismo" aparecem como sendo opostos. Os valores que os constituem situaram-se em regiões opostas, o qual significa que as suas metas são conflituosas".

Os resultados apresentados nesta pesquisa corresponderam à proposta do Inventário de Valores Organizacionais - IVO, elaborado e validado pelos autores acima citados, uma vez que, os valores referentes a Hierarquia e Igualitarismo resultaram em maior e menor média respectivamente. Este resultado demonstra uma predominância pela estrutura de poder hierárquico nos valores organizacionais da instituição.

Quanto às relações de poder e processo de trabalho, Kanaane $(1999$, p. 23) diz o seguinte:

A limitada participação nos processos produtivos tem ocasionado o descompromisso do trabalhador, gerando impedimentos que atuam tanto em termos individuais como grupais. Os problemas daí advindos estendem-se ao contexto em que o trabalho é realizado, ocasionando entraves em sua organização e no nível de satisfação dos funcionários, principalmente no tocante à necessdade de integração e de reconhecimento.

Por fim, diante do que foi descrito sobre valores organizacionais entende-se que o comprometimento do indivíduo com a sua organização de trabalho está intrinsecamente 
relacionado com a escala dos valores, que são fatores determinantes na conduta do trabalhador e da sua responsabilidade com a função que exerce.

\section{CONSIDERAÇÕES FINAIS}

Os aspectos comportamentais nas organizações têm levado estudiosos a investigar o assunto sobre valores pessoais e organizacionais, tendo em vista que os indivíduos possuem valores próprios, crenças, desejos e ambições que influenciam no comportamento organizacional e que também variam por diversos motivos. Os valores da organização são, na realidade, os valores compartilhados pelos indivíduos que dela fazem parte.

Tamayo (2000) considera os valores da organização a partir do julgamento de indivíduos, defendendo que é a partir da percepção dos servidores que são definidas as atitudes e os comportamentos. Nessa perspectiva, a pesquisa buscou identificar valores predominantes no Campus de Currais Novos, entendendo que a instituição pesquisada está inserida num contexto organizacional comprometida com a missão de educar, produzir e disseminar o saber universal, contribuir para o desenvolvimento humano, comprometendo-se com a justiça social, a democracia e a cidadania.

A pesquisa buscou, além de identificar os valores organizacionais do Campus de Currais Novos, contribuir, a partir dos valores identificados, para o desenvolvemento de estratégias que possibilitem utilizar as habilidades e competências das pessoas com maior integração e desenvolvimento dentro do atual cenário organizacional.

Os resultados encontrados revelaram uma pequena relevância de valores hierárquicos que influenciam na construção dos valores organizacionais. Os demais valores resultaram numa avaliação também mediana, em menor escala, significando que estes valores têm menor importância para a organização.

Diante dos resultados de menor importância para os valores relacionados a igualitarismo sugerimos, a instituição pesquisada, que haja uma reflexão sobre o ambiente de trabalho com o intuito de aflorar comportamentos mais afetivos que possibilitem maior comprometimento, satisfação e envolvimento dos servidores nos mais diversos processos executados e atividades desenvolvidas no Campus de Currais Novos.

\section{REFERÊNCIAS BIBLIOGRÁFICAS}

1. BERGAMINI, Cecília Whitaker. Psicologia aplicada à administração de empresas: psicologia do comportamento organizacional. São Paulo: Atlas, 2008.

2. DELFINO, Islania Andrade de Lira [et. al]. A relação entre valores pessoais e organizacionais comparados aos princípios do cooperativismo. Revista interinstitucional de psicologia. 2010. Disponível em: www.fafich.ufmg.br/. Acesso em 08 de mai. 2011.

3. DOMENICO, Marcia Russi de. LATORRE, Sidney Zaganin. A relação entre tipos de cultura organizacional valores organizacionais. In. Valores humanos \& gestão: novas perspectivas/ Maria Luiza Mendes Teixeira (org.). São Paulo: Ed. SENAC, 2008.

4. GOMES, Danilo Cortez. Valores pessoais e gestão do conhecimento organizacional. RAUP Revista eletrônica - Mestrado em Administração. 2009, p. 21-33. Disponível em: 
http://portal.unp.br/sis/templates/UnP/File/RAUnP-Ano1v1n2Abr-Out2009.pdf. Acesso em: 02 de jun. 2011.

5. GOUVEIA, Valdiney V. [et.al]. Teoria funcionalista dos valores humanos. In. Valores humanos \& gestão: novas perspectivas/ Maria Luiza Mendes Teixeira (org.). São Paulo: Ed. SENAC, 2008.

6. KANAANE, Roberto. Comportamento humano nas organizações: o homem rumo ao século XXI. São Paulo: Atlas, 1999.

7. ROBBINS, Stephen P. Comportamento Organizacional. Tradução Cristina Ávila de Menezes. Rio de Janeiro: LTC. 1998.

8. RODRIGUES, Zuleide Ribeiro. FREIRE JUNIOR, Luciano Galvão. Comprometimento organizacional e valores éticos. In Valores éticos e comprometimento dos servidores públicos do Rio Grande do Norte: relatórios de pesquisas / Zuleide Ribeiro Rodrigues (coord.). Natal: Construgof, 2002.

9. TAMAYO, Alvaro; MENDES, Ana Magnólia; PAZ, Maria das Graças Torres. Inventário de valores organizacionais. Artigos - Estudos de Psicologia. 2000, p. 289-315. Disponível em: http://www.scielo.br/pdf/epsic/v5n2/a02v05n2.pdf. Acesso em 28 de abr. 2011.

10. TAMAYO, Álvaro. GONDIM, Maria das Graças Catunda. Artigo Escala de valores organizacionais. Revista de Administração, São Paulo: v. 31, n. 2, abril/junho/1996. Disponível em www.rausp.usp.br/busca/artigo.asp? Acesso em 28 de abr. 2011.

11. TAMAYO, Álvaro. Valores organizacionais: sua relação com satisfação no trabalho, cidadania organizacional e comprometimento afetivo. Revista de Administração, São Paulo: v. 33, n. 3, 1998. Disponível em www.rausp.usp.br. Acesso em 25 de abr. 2011.

12. ZANELLA, Liane Carly Hermes. Metodologia da pesquisa. Florianópolis: SEAD/UFSC, 2006.

\section{ANEXO 1}

\section{INVENTÁRIO DE VALORES ORGANIZACIONAIS}

Este questionário traz uma lista de itens que expressam valores da organização. Sua tarefa é avaliar quão importantes são esses valores como princípios orientadores da vida da sua organização. Esta avaliação deve ser feita em dois níveis:

Real: quanto cada item é importante na realidade atual da sua organização.

Desejável: quanto cada item deveria ser importante para sua organização.

Para dar sua opinião, utilize uma escala de 0 a 6, conforme abaixo:

\begin{tabular}{ccccccc}
\hline I & I & $\mid$ & $l$ & $\mid$ & $\mid$ & $\mid$ \\
$\begin{array}{c}\text { Nada } \\
\text { Importante }\end{array}$ & 1 & 2 & 3 & 4 & 5 & $\begin{array}{c}\text { Extremamente } \\
\text { importante }\end{array}$ \\
\hline
\end{tabular}

Lembre-se de que quanto mais próximo do 6 mais importante é o valor.

Coloque um círculo em torno do número escolhido para cada um dos aspectos -Real e Desejável- na coluna correspondente. 
Não há resposta certa ou errada. Responda de acordo com o seu entendimento e interpretação. Por favor, não deixe nenhum item em branco.

Agradecemos a sua valiosa colaboração. Não é necessário se identificar.

Item

1. Capacidade de inovar na organização

2. Capacidade de realizar as tarefas sem necessidade de supervisão constante

3. Introdução de novidades no trabalho

4. Abertura para expor sugestões e opiniões sobre o trabalho

5. Busca constante de informação e novidades

6. Continuidade de políticas e projetos organizados

7. Fidelidade e organização

8. Integridade de pessoas e bens

9. Preservação dos costumes vigentes da organização

10 Tradição de respeito às ordens

11 Clima de ajuda mútua

12 Distribuição do poder pelos diversos níveis

13 Tratamento proporcional ao mérito

14

Oportunidades iguais para todos os funcionários

15 Imparcialidade nas decisões administrativas

16 Clima de relacionamento amistoso entre os empregados

17 Respeito às pessoas com cargo de chefia

18 Respeitar as regras e normas estabelecidas pela organização

19 Controle do serviço executado

20 Respeito aos níveis de autoridade
RReal

\begin{tabular}{|l|l|l|l|l|l|l|}
\hline 0 & 1 & 2 & 3 & 4 & 5 & 6 \\
\hline 0 & 1 & 2 & 3 & 4 & 5 & 6 \\
\hline
\end{tabular}

$\begin{array}{llllllll}0 & 1 & 2 & 3 & 4 & 5 & 6\end{array}$

$\begin{array}{llllllll}0 & 1 & 2 & 3 & 4 & 5 & 6\end{array}$

$\begin{array}{llllllll}0 & 1 & 2 & 3 & 4 & 5 & 6\end{array}$

$\begin{array}{llllllll}0 & 1 & 2 & 3 & 4 & 5 & 6\end{array}$

$\begin{array}{llllllll}0 & 1 & 2 & 3 & 4 & 5 & 6\end{array}$

$\begin{array}{llllllll}0 & 1 & 2 & 3 & 4 & 5 & 6\end{array}$

$\begin{array}{llllllll}0 & 1 & 2 & 3 & 4 & 5 & 6\end{array}$

$\begin{array}{llllllll}0 & 1 & 2 & 3 & 4 & 5 & 6\end{array}$

$\begin{array}{llllllll}0 & 1 & 2 & 3 & 4 & 5 & 6\end{array}$

$\begin{array}{llllllll}0 & 1 & 2 & 3 & 4 & 5 & 6\end{array}$

$\begin{array}{llllllll}0 & 1 & 2 & 3 & 4 & 5 & 6\end{array}$

$\begin{array}{llllllll}0 & 1 & 2 & 3 & 4 & 5 & 6\end{array}$

$\begin{array}{lllllll}0 & 1 & 2 & 3 & 4 & 5 & 6\end{array}$

\begin{tabular}{llllllll|}
0 & 1 & 2 & 3 & 4 & 5 & 6
\end{tabular}

$\begin{array}{lllllll}0 & 1 & 2 & 3 & 4 & 5 & 6\end{array}$

$\begin{array}{lllllll}0 & 1 & 2 & 3 & 4 & 5 & 6\end{array}$

$\begin{array}{llllllll}0 & 1 & 2 & 3 & 4 & 5 & 6\end{array}$

$\begin{array}{llllllll}0 & 1 & 2 & 3 & 4 & 5 & 6\end{array}$
DDesejável

\begin{tabular}{|l|l|l|l|l|l|l|}
\hline 0 & 1 & 2 & 3 & 4 & 5 & 6 \\
\hline 0 & 1 & 2 & 3 & 4 & 5 & 6 \\
\hline 0 & 1 & 2 & 3 & 4 & 5 & 6 \\
\hline
\end{tabular}

$\begin{array}{lllllll}0 & 1 & 2 & 3 & 4 & 5 & 6\end{array}$

$\begin{array}{lllllll}0 & 1 & 2 & 3 & 4 & 5 & 6\end{array}$

$\begin{array}{llllllll}0 & 1 & 2 & 3 & 4 & 5 & 6\end{array}$

$\begin{array}{llllllll}0 & 1 & 2 & 3 & 4 & 5 & 6\end{array}$

$\begin{array}{llllllll}0 & 1 & 2 & 3 & 4 & 5 & 6\end{array}$

$\begin{array}{llllllll}0 & 1 & 2 & 3 & 4 & 5 & 6\end{array}$

$\begin{array}{lllllll}0 & 1 & 2 & 3 & 4 & 5 & 6\end{array}$

$\begin{array}{llllllll}0 & 1 & 2 & 3 & 4 & 5 & 6\end{array}$

$\begin{array}{llllllll}0 & 1 & 2 & 3 & 4 & 5 & 6\end{array}$

$\begin{array}{lllllll}0 & 1 & 2 & 3 & 4 & 5 & 6\end{array}$

$\begin{array}{llllllll}0 & 1 & 2 & 3 & 4 & 5 & 6\end{array}$

$\begin{array}{llllllll}0 & 1 & 2 & 3 & 4 & 5 & 6\end{array}$

\begin{tabular}{llllllll}
\hline 0 & 1 & 2 & 3 & 4 & 5 & 6
\end{tabular}

$\begin{array}{lllllll}0 & 1 & 2 & 3 & 4 & 5 & 6\end{array}$

$\begin{array}{llllllll}0 & 1 & 2 & 3 & 4 & 5 & 6\end{array}$

$\begin{array}{lllllll}0 & 1 & 2 & 3 & 4 & 5 & 6\end{array}$

$\begin{array}{llllllll}0 & 1 & 2 & 3 & 4 & 5 & 6\end{array}$ 


\begin{tabular}{|c|c|c|c|c|c|c|c|c|c|c|c|c|c|c|c|}
\hline 21 & $\begin{array}{l}\text { Capacidade de influenciar pessoas na } \\
\text { organização }\end{array}$ & 0 & 1 & 2 & 3 & 4 & 5 & 6 & 0 & 1 & 2 & 3 & 4 & 5 & 6 \\
\hline 22 & $\begin{array}{l}\text { Preocupação com o cumprimento de horários } \\
\text { e compromissos }\end{array}$ & 0 & 1 & 2 & 3 & 4 & 5 & 6 & 0 & 1 & 2 & 3 & 4 & 5 & 6 \\
\hline 23 & $\begin{array}{l}\text { Dificuldade de alterar regras, normas e } \\
\text { comportamentos na organização }\end{array}$ & 0 & 1 & 2 & 3 & 4 & 5 & 6 & 0 & 1 & 2 & 3 & 4 & 5 & 6 \\
\hline 24 & $\begin{array}{l}\text { Acompanhamento e avaliação contínuos das } \\
\text { tarefas }\end{array}$ & 0 & 1 & 2 & 3 & 4 & 5 & 6 & 0 & 1 & 2 & 3 & 4 & 5 & 6 \\
\hline 25 & $\begin{array}{l}\text { Ambiente de relacionamento } \\
\text { interorganizacional adequado }\end{array}$ & 0 & 1 & 2 & 3 & 4 & 5 & 6 & 0 & 1 & 2 & 3 & 4 & 5 & 6 \\
\hline 26 & Complementariedade de papéis entre organiz. & 0 & 1 & 2 & 3 & 4 & 5 & 6 & 0 & 1 & 2 & 3 & 4 & 5 & 6 \\
\hline 27 & $\begin{array}{l}\text { Utilização de recursos sem causar danos ao } \\
\text { meio ambiente }\end{array}$ & 0 & 1 & 2 & 3 & 4 & 5 & 6 & 0 & 1 & 2 & 3 & 4 & 5 & 6 \\
\hline 28 & Proteção ao meio ambiente & 0 & 1 & 2 & 3 & 4 & 5 & 6 & 0 & 1 & 2 & 3 & 4 & 5 & 6 \\
\hline 29 & Intercâmbio com outras organizações & 0 & 1 & 2 & 3 & 4 & 5 & 6 & 0 & 1 & 2 & 3 & 4 & 5 & 6 \\
\hline 30 & Atuação conjunta com outras empresas & 0 & 1 & 2 & 3 & 4 & 5 & 6 & 0 & 1 & 2 & 3 & 4 & 5 & 6 \\
\hline 31 & Busca de melhor posição no mercado & 0 & 1 & 2 & 3 & 4 & 5 & 6 & 0 & 1 & 2 & 3 & 4 & 5 & 6 \\
\hline 32 & $\begin{array}{l}\text { Conquista de clientes em relação à } \\
\text { concorrência }\end{array}$ & 0 & 1 & 2 & 3 & 4 & 5 & 6 & 0 & 1 & 2 & 3 & 4 & 5 & 6 \\
\hline 33 & $\begin{array}{l}\text { Manutenção da superioridade em relação ao } \\
\text { mercado }\end{array}$ & 0 & 1 & 2 & 3 & 4 & 5 & 6 & 0 & 1 & 2 & 3 & 4 & 5 & 6 \\
\hline 34 & $\begin{array}{l}\text { Preocupação com o aumento da produção e } \\
\text { prestação dos serviços }\end{array}$ & 0 & 1 & 2 & 3 & 4 & 5 & 6 & 0 & 1 & 2 & 3 & 4 & 5 & 6 \\
\hline 35 & Êxitos nos empreendimentos organizacionais & 0 & 1 & 2 & 3 & 4 & 5 & 6 & 0 & 1 & 2 & 3 & 4 & 5 & 6 \\
\hline 36 & $\begin{array}{l}\text { Agir de forma arrojada em relação às outras } \\
\text { empresas }\end{array}$ & 0 & 1 & 2 & 3 & 4 & 5 & 6 & 0 & 1 & 2 & 3 & 4 & 5 & 6 \\
\hline
\end{tabular}

REFERÊNCIA: TAMAYO, Alvaro; MENDES, Ana Magnólia; PAZ, Maria das Graças Torres. Inventário de valores organizacionais. Artigos - Estudos de Psicologia, 2000, 5(2), 289-315. 